\title{
ОЦЕНКА КОРРЕЛЯЦИОННЫХ ВЗАИМОСВЯЗЕЙ
} МОРФОФИЗИОЛОГИЧЕСКИХ ПРИЗНАКОВ ЗЕРНОВОГОСОРГО СЕЛЕКЦИИ ФГБНУ РОСНИИСК «РОССОРГО»

\author{
СТАРЧАК Виктория Игоревна, Саратовский государственный аграрный университет \\ имени Н.И. Вавилова \\ ЖУЖУКИН Валерий Иванович, Саратовский государственный аграрный университет \\ имени Н.И. Вавилова
}

ЖУк Екатерина Александровна, ФГБНУ Российский научно-исследовательский и проектно-технологический институт сорго и кукурузы «Россорго»

БЫЧковА Вера Валерьевна, ФГБНУ Российский научно-исследовательский и проектнотехнологический институт сорго и кукурузы «Россорго»

В современных условиях необходимость возделывания зернового сорго в регионах с недостаточным увлажнением определяется его высокой урожайностью и качеством зерна. Для практической селекиии с иелью оценки корреляционных взаимосвязей 19 морфофизиологических признаков в модельную популяцию включили 15 сортов и 2 перспективные линии зернового сорго, созданных в ФГБНУ РосНИИСК «Россорго». Биохимический состав зерна объектов исследований представлен графически.

Выявлена различная степень варъирования признаков зернового сорго: очень сильная (V>40,0 \%) продуктивная кустистость, число зерен с 1 метелки; сильная $(20,0 \%<V<40,0$ \%) - ширина метелки, въдвинутость ножки метелки, толщина верхнего междоузлия, площадъ флагового листа, площадъ наибольшего листа, масса зерна с 1 метелки; слабая (V<10,0\%) - высота растений через 30 сут., высота растений при созревании. К группе со средней степенъю варьирования $(10,0 \%<V<20,0 \%)$ относятся все другие признаки, измеряемые в опыте. Факторный анализ использовали с иелью оптимизаиии, интерпретации рассчитанной матрицы коэффициентов корреляции. При анализе матрищы коэффициентов корреляции рассчитаны гипотетические факторы с вкладом более 5 \% в накапливаемую дисперсию. Первый гипотетический фактор определяется высокими эффектами морфофизиологических признаков. Второй фактор в большей мере обусловлен вкладом высоты растений через $30 \mathrm{cym.} \mathrm{после} \mathrm{появления} \mathrm{всходов} \mathrm{и}$ выдвинутостью ножки метелки. Высота растений при созревании, масса 1000 зерен дают наибольший вклад в третий фактор. В накапливаемую дисперсию четвертого фактора наибольший вклад вносит ширина метелки. Пятый фактор определяется эффектами высоты растений в начале и конце вегетаици, а также суммарным вкладом всех изучаемых признаков.

Введение. В регионах с недостаточным увлажнением целесообразность выращивания сортов и гибридов зернового сорго определяется урожайностью и качеством его продукции $[9,11,14]$. Урожайность сорго зависит от генотипических особенностей сортов и гибридов и уровня агротехники, а также почвенно-климатических условий микрозоны выращивания $[12,13]$.

Поскольку зерновое сорго превосходит многие полевые культуры по засухоустойчивости и жаростойкости, оно является важной страховой культурой на случай возникновения засухи в летний период и чаще всего имеет преимущество при использовании в качестве пожнивной или поукосной культуры [10]. Некоторые исследователи отмечают мелиорирующую роль зернового сорго при посеве на засоленных почвах $[1,2]$.

Изучение биохимических показателей, характеризующих качество зерна сорго, является необходимым условием эффективной селекционной работы. Выявлено, что биохимический состав зерна зависит от многих факторов: генотипа, погодных и экологических условий, числа растений на единицу площади, уровня технологий, включа- ющий и интегрированную систему защиты растений от болезней и вредителей $[15,16]$.

Цель исследований - определение корреляционных взаимосвязей морфофизиологических признаков модельной популяции зернового сорго.

Методика исследований. Объектом исследований являлись модельная популяция зернового сорго, состоящая из сортов и сортообразцов, созданных в ФГБНУ РосНИИСК «Россорго» и включенных или переданных в Госсорткомиссию (РСК Оникс) в реестр охраняемых и селекционных достижений [3]. Посев проводили на опытном поле ФГБНУ РосНИИСК «Россорго» в 2015-2017 гг. широкорядным способом с междурядьем 70 см. Общая площадь делянки составила $7,7 \mathrm{~m}^{2}$, а уборочная $-7,0 \mathrm{M}^{2}$. Общая площадь опыта составила $392,7 \mathrm{~m}^{2}$ с защитными полосами 510,5 м². Повторность - трехкратная. Размещение делянок рендомизированное.

Технология возделывания включает следующие агротехнологические мероприятия. Предшественник- чистый пар. Весной проводили боронование и 2 культивации. Посев осуществляли селекционной кассетной сеялкой СКС-6-10. Уход 
за посевами включал две междурядные обработки культиватором.

В фазу 3-4 листьев вручную корректировали число растений (110 тыс. раст./га). Уборку урожая проводили вручную. Учеты и наблюдения - согласно Широкому унифицированному классификатору СЭВ и международного классификатора СЭВ возделываемых видов рода Sorghum Moench [17]. Статистическая обработка результатов исследований выполнена с помощью программы «AGROS 2.09».

Биохимический состав зерна оценивали в лаборатории биохимии и биотехнологии ФГБНУ РосНИИСК «Россорго» по следующим методикам: протеин по Кьельдалю (прибор KjeltecSystem 2100)[4], «сырой» жир по методу Сосклета [5], золу методом сухого озоления [6], «сырую» клетчатку по ГОСТ 13496.2-91 [7], крахмал по ГОСТ 10845-98 [8], БЭВ рассчитывали по общепринятой формуле Венде.

Опытное поле института ФГБНУ РосНИИСК «Россорго» расположено в южной правобережной микрозоне Саратовской области. Почва представлена южным черноземом, слабовыщелоченным, среднесуглинистым по механическому составу. Содержание в слое 0-40 см гумуса в этих черноземах составляет 3,5-4,2 \%, обменная способность - 17-31 мг-экв. на 100 г почвы. Количество доступных форм питательных веществ варьирует в широких пределах. Содержание гидролизуемого азота составляет 10 мг, фосфора 7,2 мг, обменного калия - 21 мг, кальция - 8 мг на 100 г почвы. Гидротермический коэффициент в годы исследования составил в 2015 г. - 0,41, 2016 г. - 0,64; 2017 г.- 0,71.

Результаты исследований. По изучаемым признакам в опыте установлено значительное варьирование хозяйственно-ценных признаков в годы исследований (табл. 1,2). Интервалы значений по признакам составляли: высота растений через 30 дней от 43,9 до 65,8 см; высота растений при созревании от 101,5 до 143,0 см; длина флагового листа от 18,0 до 34,2 см; ширина флагового листа от 2,20 до 4,80 см; длина наибольшего листа от 32,2 до 52,7 см; ширина наибольшего листа от 3,37 до 6,07 см; площадь флагового листа от 38,3 до 102,0 cм²; площадь наибольшего листа от 80,9 до 217,2 см$^{2}$; общая кустистость от 1,23 до 2,09; продуктивная кустистость от 1,27 до 4,20; толщина верхнего междоузлия от 0,39 до 1,03 см; толщина нижнего междоузлия от 0,74 до 1,76 см; выдвинутость ножки метелки от 0,7 до 30,0 см; длина метелки от 9,9 до 28,8 см; ширина метелки от 4,9 до 16,5 см; масса зерна с 1 зерна метелки от 5,2 до 33,7 г; число зерен с 1 метелки от 195 до 1329 шт.; масса 1000 зерен от 19,3 до 37,9 г; урожайность зерна от 3,18до 5,57 т/га.

В модельной популяции зернового сорго выявлена различная степень варьирования признаков: очень сильная ( $V>40,0$ \%) - продуктивная кустистость, число зерен с 1 метелки; сильная (20,0 \% < $6<40,0$ \%) - ширина метелки, вы- двинутость ножки метелки, толщина верхнего междоузлия, площадь флагового листа, площадь наибольшего листа, масса зерна с 1 метелки; слабая $(V<10,0$ \%) - высота растений через 30 сут., высота растений при созревании (табл. $1,2,3)$. В группу со средней степенью варьирования (10,0\%< $<<20,0$ \%) относили все другие признаки, измеряемые в опыте.

Значимую корреляционную связь $(r \geq 0,482)$ урожайности зерна сорго выявили со следующими признаками: а) положительная - длина метелки, длина наибольшего листа, ширина наибольшего листа, толщина верхнего междоузлия, толщина нижнего междоузлия, площадь флагового листа, площадь наибольшего листа, число зерен с 1 метелки, масса зерна с 1 метелки; б) отрицательная - общая кустистость, продуктивная кустистость.

Выявили существенные коэффициенты корреляция числа зерен с метелки и следующих признаков: длина и ширина наибольшего листа, толщина верхнего и нижнего междоузлий, площадь флагового листа. Число зерен отрицательно коррелирует с выдвинутостью ножки метелки, общей и продуктивной кустистостью. Не установили корреляционной связи массы 1000 зерен с рассматриваемыми вегетативными и генеративными признаками зернового сорго. Следует отметить, что коэффициент корреляции массы 1000 зерен и числа зерен с 1 метелки отражает определенные их конкурентные отношения $(r=-0,481)$.С целью системного обсуждения рассчитанной матрицы коэффициентов корреляции (всего 171) использовали факторный анализ (табл. 3).

Оценку качественного состава основной продукции провели с целью определения питательной ценности зерна сорго (см. рисунок).

Размах варьирования показателей качества выявили в следующих пределах: протеин 9,65$13,09 \%$, жир 3,10-4,81 \%, зола 1,37-1,89 \%, клетчатка 1,68-2,97 \%, БЭВ 77,99-84,32 \%, крахмал 72,52-77,29 \%. Однако существенные различия обнаружены только по содержанию клетчатки. По другим показателям, определяющим биохимический состав зерна сорго, достоверных различий не обнаружено на 5\%-м уровне значимости.

Заключение.Проведенный анализ морфофизиологических признаков и биохимических показателей качества зерна позволяет сделать вывод о том, что исследуемые сорта зернового сорго, допущенные к использованию, отличаются сравнительно высокой урожайностью (более 5,0 т/га) и качеством зерна. Выявлены значимые положительные коэффициенты корреляции урожайности зерна сорго с длиной метелки, длиной и шириной наибольшего листа, толщиной верхнего и нижнего междоузлия, площадью флагового и наибольшего листа, числом зерен с 1 метелки и массы зерна с 1 метелки. Общая и продуктивная кустистость, толщина верхнего и нижнего междоузлия, параметры наибольшего листа вносят 


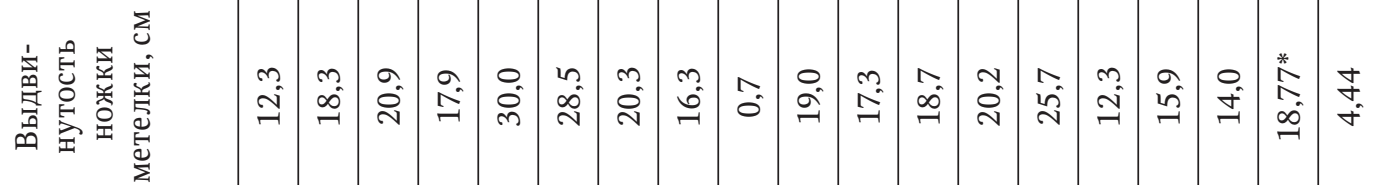

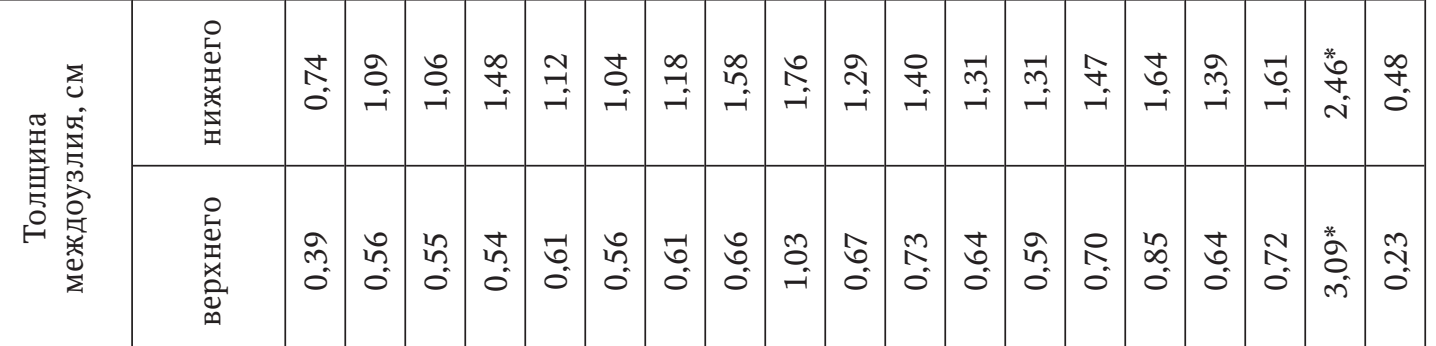

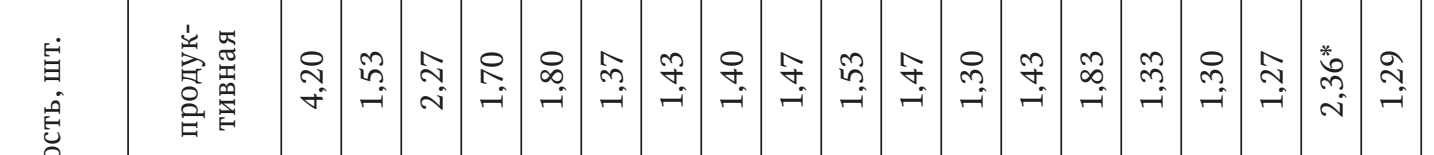

\begin{tabular}{|c|c|c|c|c|c|c|c|c|c|c|c|c|c|c|c|c|c|c|c|}
\hline $\begin{array}{l}\frac{5}{\sigma} \\
\stackrel{\Xi}{0} \\
0\end{array}$ & $\stackrel{\text { oे }}{\text { i }}$ & N & $\underset{ت}{\stackrel{ \pm}{*}}$ & 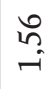 & $\stackrel{f}{f}$ & $\stackrel{\tilde{m}}{-}$ & 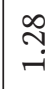 & $\underset{\sim}{\sim}$ & $\underset{-}{\vec{F}}$ & $\underset{i}{q}$ & $\underset{\sim}{\sim}$ & $\underset{\sim}{\stackrel{f}{f}}$ & $\begin{array}{l}0 \\
\stackrel{+}{-} \\
-1\end{array}$ & & & & & 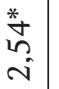 & $\stackrel{\infty}{+\infty}$ \\
\hline
\end{tabular}

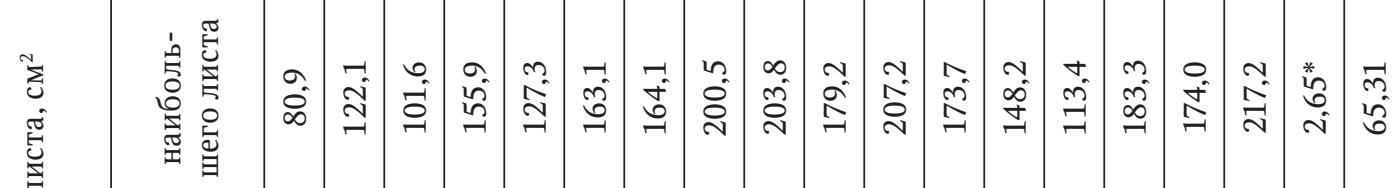

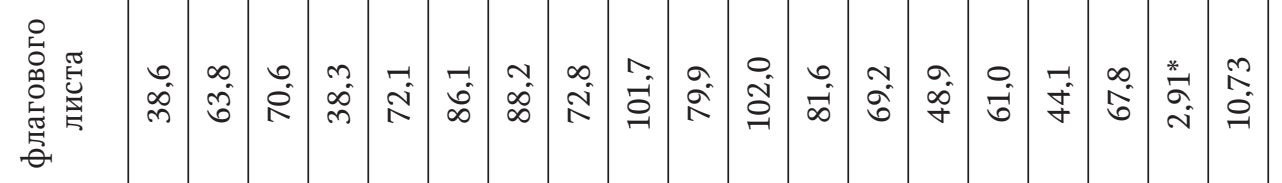

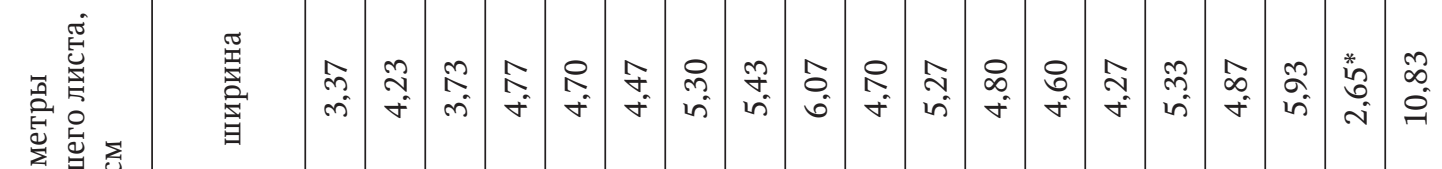

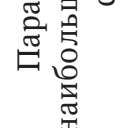

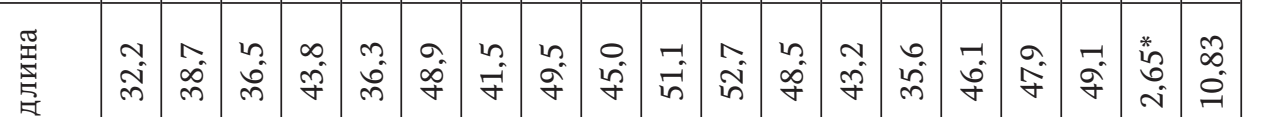

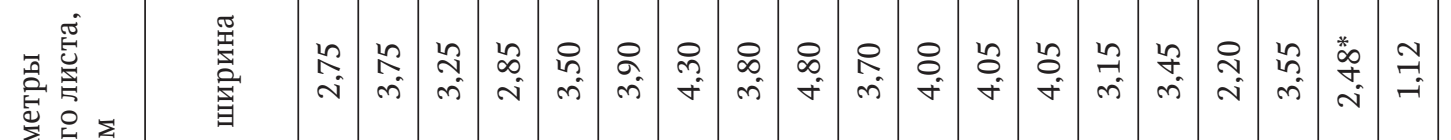

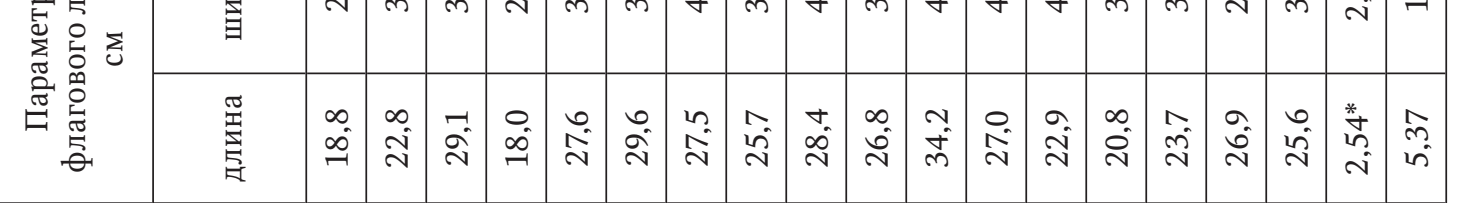

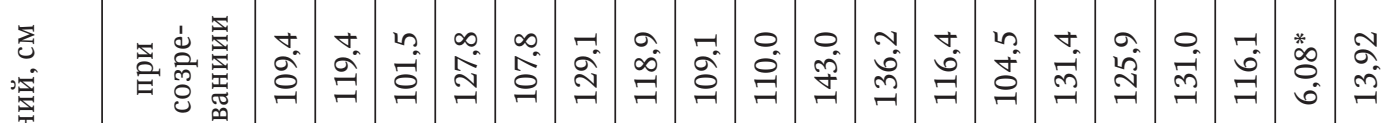

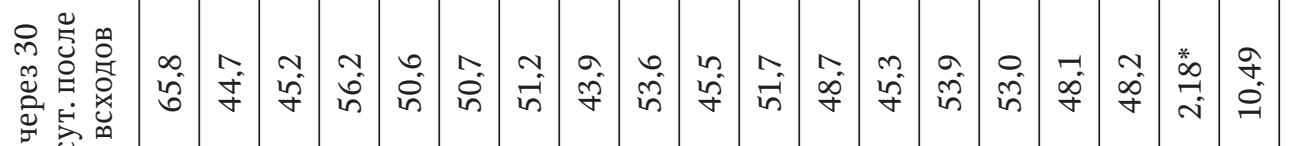


Средние значения генеративных признаков сортообразцов зернового сорго, 2015-2017 гг.

\begin{tabular}{|c|c|c|c|c|c|c|}
\hline Сорт / сортообразец & $\begin{array}{c}\text { Длина } \\
\text { метелки, } \\
\text { см } \\
\end{array}$ & $\begin{array}{c}\text { Ширина } \\
\text { метелки, } \\
\text { см } \\
\end{array}$ & $\begin{array}{c}\text { Масса } \\
\text { зерна с } 1 \\
\text { метелки, г }\end{array}$ & $\begin{array}{c}\text { Число } \\
\text { зерен с } 1 \\
\text { метелки, } \\
\text { шт. }\end{array}$ & $\begin{array}{c}\text { Масса } 1000 \\
\text { зерен, г }\end{array}$ & $\begin{array}{c}\text { Урожайность } \\
\text { зерна, т/га }\end{array}$ \\
\hline Перспективный 1 & 9,9 & 4,9 & 5,2 & 195 & 27,2 & 3,18 \\
\hline Меркурий & 24,0 & 12,6 & 11,5 & 602 & 19,3 & 4,83 \\
\hline Огонек & 21,2 & 10,4 & 12,6 & 458 & 28,7 & 4,23 \\
\hline Кремовое & 22,1 & 14,6 & 15,9 & 614 & 28,2 & 4,53 \\
\hline Старт & 19,4 & 9,4 & 11,7 & 432 & 28,8 & 4,46 \\
\hline РСК Оникс & 21,7 & 8,1 & 16,0 & 564 & 28,6 & 5,57 \\
\hline Восторг & 19,4 & 8,0 & 17,8 & 597 & 31,2 & 4,34 \\
\hline Гранат & 20,3 & 6,4 & 17,9 & 527 & 33,6 & 4,74 \\
\hline Камелик & 21,9 & 9,2 & 21,2 & 1323 & 20,2 & 5,38 \\
\hline Волжское 4 & 24,2 & 8,1 & 22,4 & 817 & 27,5 & 4,83 \\
\hline Волжское 44 & 28,8 & 16,5 & 19,4 & 832 & 23,9 & 5,21 \\
\hline Волжское 615 & 26,6 & 13,9 & 17,3 & 626 & 29,5 & 4,25 \\
\hline Пищевое 35 & 24,1 & 13,0 & 20,9 & 837 & 25,9 & 4,31 \\
\hline Сармат & 15,1 & 7,7 & 16,0 & 430 & 37,9 & 4,83 \\
\hline Аванс & 25,2 & 9,6 & 23,3 & 639 & 36,8 & 5,53 \\
\hline Факел & 23,1 & 11,6 & 23,0 & 869 & 27,9 & 5,07 \\
\hline Магистр & 19,4 & 10,1 & 33,7 & 1329 & 25,4 & 5,34 \\
\hline $\mathrm{F}_{\text {факт }}$ & $6,54^{*}$ & $3,14^{*}$ & $3,96^{*}$ & $3,03^{*}$ & $3,35^{*}$ & $2,51^{*}$ \\
\hline $\mathrm{HCP}_{0,05}$ & 4,89 & 4,97 & 9,00 & 449,83 & 7,65 & 0,83 \\
\hline
\end{tabular}

Таблица 3

Факторные нагрузки модельной популяции зернового сорго, 2015-2017 гг.

\begin{tabular}{|l|c|c|c|c|c|}
\hline \multicolumn{1}{|c|}{ Признак } & \multicolumn{5}{c|}{ Фактор } \\
\cline { 2 - 6 } & $Z 1$ & $Z 2$ & $Z 3$ & $Z 4$ & $Z 5$ \\
\hline Высота растений через 30 сут. & $-0,446$ & 0,542 & $-0,142$ & $-0,068$ & $-0,516$ \\
\hline Высота растений при созревании & 0,298 & $-0,202$ & $-0,619$ & $-0,258$ & $-0,570$ \\
\hline Длина метелки & 0,743 & $-0,450$ & 0,089 & $-0,335$ & $-0,025$ \\
\hline Ширина метелки & 0,402 & $-0,340$ & 0,141 & $-0,717$ & 0,004 \\
\hline Длина флагового листа & 0,561 & $-0,451$ & 0,334 & 0,293 & $-0,320$ \\
\hline Ширина флагового листа & 0,556 & $-0,021$ & 0,504 & 0,454 & $-0,092$ \\
\hline Длина наибольшего листа & 0,834 & $-0,157$ & $-0,161$ & $-0,091$ & $-0,144$ \\
\hline Ширина наибольшего листа & 0,867 & 0,336 & $-0,035$ & 0,150 & 0,060 \\
\hline Выдвинутость ножки метелки & $-0,318$ & $-0,780$ & $-0,281$ & 0,207 & 0,102 \\
\hline Толщина верхнего междоузлия & 0,832 & 0,436 & 0,082 & 0,041 & $-0,037$ \\
\hline Толщина нижнего междоузлия & 0,809 & 0,413 & $-0,195$ & $-0,068$ & 0,243 \\
\hline Площадь флагового листа & 0,737 & $-0,173$ & 0,438 & 0,319 & $-0,311$ \\
\hline Площадь наибольшего листа & 0,701 & 0,080 & $-0,480$ & 0,186 & $-0,234$ \\
\hline Общая кустистость & $-0,820$ & 0,220 & 0,051 & $-0,094$ & $-0,285$ \\
\hline Продуктивная кустистость & $-0,861$ & 0,302 & 0,208 & $-0,010$ & $-0,254$ \\
\hline Число зерен с 1 метелки & 0,807 & 0,353 & 0,209 & $-0,192$ & 0,056 \\
\hline Масса зерна с 1 метелки & 0,801 & 0,213 & $-0,231$ & $-0,074$ & 0,217 \\
\hline Масса 1000 зерен & $-0,189$ & $-0,029$ & $-0,766$ & 0,443 & 0,163 \\
\hline Урожайность зерна & 0,796 & $-0,026$ & $-0,257$ & 0,055 & $-0,162$ \\
\hline Дисперсия & 8,926 & 2,311 & 2,165 & 1,456 & 1,198 \\
\hline Дисперсия, \% & 46,979 & 12,164 & 11,393 & 7,661 & 6,305 \\
\hline Накопленная дисперсия, \% & 46,979 & 59,142 & 70,535 & 78,196 & 84,501 \\
\hline
\end{tabular}

Примечание: Z1...Z 5 - гипотетический фактор.

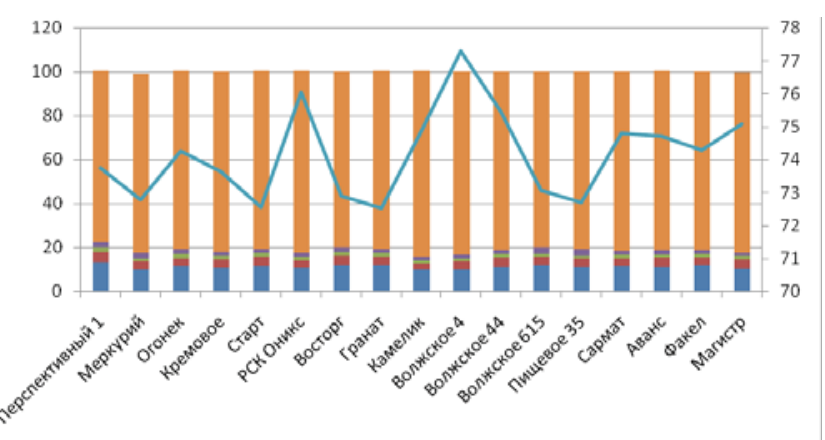

Ш Протеин Жир Ш

Биохимический состав зерна зернового сорго, 2015-2017 22. наибольший вклад в накапливаемую дисперсию основного гипотетического фактора. Значимые существенные различия по биохимическим показателям установлены только по содержанию клетчатки. Не установлено существенных различий по содержанию протеина, золы, жира и БЭВ.

\section{СПИСОК ЛИТЕРАТУРЫ}

1. Алабушев А.В., Анипенко Л.Н., Гурский Н.Г. Сорго (селекция, семеноводство, технология, экономика). Ростов н/Д: ЗАО «Книга», 2003.- 368 с. 
2. Гасанов Г.Н., Мусаев М.Р., Мамалаева А.О. Сорго не боящееся соли//Кукуруза и сорго.- 2007. - №4. C. 22-23.

3. Государственный реестр селекционных достижений, допущенных к использованию. В 2-х т. Т. 1 . -М.: ФГБНУ «Росинформагротех», 2019.-516 с.

4. ГОСТ 10846-91. Зерно и продукты его переработки. Метод определения белка. - М.: Издательство стандартов, 1992. - 10 с.

5. ГОСТ 13496.15-97. Корма, комбикорма, комбикормовое сырье. Методы определения содержания сырого жира.- М: Издательство стандартов, 1998. - 11с.

6. ГОСТ 26226-95. Корма, комбикорма, комбикормовое сырье. Методы определения сырой золы. M., 1996. -8 c.

7. ГОСТ 13496.2-91. Корма, Комбикорма, комбикормовое сырье. Метод определения сырой клетчатки. - М.: Издательство стандартов, 1992.- 9с.

8. ГОСТ 10845-98. Зерно и продукты его переработки. Метод определения крахмала. - М.: Межгосударственный стандарт, 1998. - 9с.

9. Гратило А.Д. Сорго сахарное в Южной степи Украины // Кормопроизводство.-2013. -№3. C. 30-31.

10. Дронов А.В.,Бельченко С.А., Андрюшин Е.Н. Совершенствование технологии возделывания сорговых культур// Агрохимический вестник.- 2015.-№5.-С. 22-24.

11. Жужукин В.И.,Семин Д.С. Зерновое сорго в Поволжье// Земледелие. -2013. -№5. - С. 29-30.

12. Заварзин А.И., Царе, А.П. Сорго.- Саратов: Приволжское книжное издательство, 1989.- 56 с.

13. Кадралиев Д.С., Григоренков, Е.Н. Ресурсосберегающая технология возделывания сорго в Астраханской области//Кормопроизвоство .- 2009. - №12.- С. 17-20.

14. Особенности технологии возделывания и использования сорговых культур в районах недостаточного увлажнения Юго-Востока и юга Российской Фе- дерации: рекомендации /А.Г. Ишин [и др.]. - Саратов, 2008. -54 c.

15. Царе, А.П.,Морозов Е.В. Агробиологические основы выращивания и использования сорговых культур в Поволжье/ФГОУ ВПО «Саратовский ГАУ». - Саратов, 2011. - 244 c.

16.Шепел, Н.А. Сорго.- Волгоград, 1994.- 448 с.

17. Широкий унифицированный классификатор СЭВ и международный классификатор СЭВ возделываемых видов рода Sorghum Moench. ВНИИР им. Н.И. Вавилова (ВИР). Рекомендации Е.С. Якушевский[и др.]-Ленинград, 1982. -34 с.

Старчак Виктория Игоревна, аспирант кафедры «Растениеводство, селекиия игенетика», Саратовский государственный аграрный университет имени Н.И. Вавилова. Россия.

Жужукин Валерий Иванович, $\partial-p$ c.- $x$. наук, проф. кафедры «Растениеводство, селекиия и генетика», Саратовский государственный аграрный университет имени Н.И. Вавилова. Россия.

410012, г. Саратов, Театральная пл., 1.

Тел.: (8452) 23-32-92.

Жук Екатерина Александровна, канд. с.-х. наук, и.о. заместителя директора по научной работе и международному сотрудничеству, ФГБНУ Российский научно-исследовательский и проектно-технологический институт сорго и кукурузы «Россорго». Россия.

Бычкова Вера Валерьевна, и.о. ученого секретаря, ФГБНУ Российский научно-исследовательский и проектно-технологический институт сорго и кукуру361 «оссорго». Россия.

410050, г.Саратов, 1-й институтский пр-д, 4.

Тел.: 8(8452) 79-49-69.

Ключевые слова: сорго; фактор; анализ; высота растений; масса 1000 зерен; продуктивность; урожайность; число зерен; длина; ширина; лист.

\section{ASSESSMENT OF THE CORRELATION OF INTERRELATIONS OF MORPHOLOGICAL CHARACTERISTICS OF THE GRAIN SORGHUM}

Starchak Victoria Igorevna, Ppost-graduate Student of the chair "Crop Production, Selection and Genetics", Saratov State Agrarian University named after N.I. Vavilov, Russia.

Zhuzhukin Valery Ivanovich, Doctor of Agricultural Sciences, Professor of the chair "Crop Production, Selection and Genetics”, Saratov State Agrarian University named after N. I. Vavilov, Russia.

Zhuk Ekaterina Aleksandrovna, Candidate of Agricultural Sciences, Chief Researcher, All-Russian Research Institute for Sorghum and Maize "Rossorgo". Russia.

Bychkova Vera Valeryevna, All-Russian Research Institute for Sorghum and Maize "Rossorgo". Russia.

Keywords: sorghum; factor; analysis; plant height; weight of 1000 grains; productivity; yield; number of grains; length; width; leaf.

In modern conditions, the need for cultivation of grain sorghum in regions with insufficient moisture is determined by its high yield and grain quality. For practical breeding, with the objective of assessing linkages 19 morphological and physiological traits model of the population including 15 varieties and 2 promising lines of grain sorghum that is created in the Russian Research and Design Technological Institute of Sorghum and Maize. The biochemical composition of the grain of the objects of research is presented graphically.
A different degree of variation in the characteristics of grain sorghum was revealed: very strong $(V>40,0 \%)$ - productive bushiness, number of grains from 1 panicle; strong $(20,0 \%<V<40,0 \%)$ - the width of the panicle, the extension of the panicle leg, the thickness of the upper internode, the area of the flag leaf, the area of the fourth on top of the leaf, the mass of the grain from 1 panicle; weak $(V<10,0 \%)$ - the height of the plants after 30 days, the height of the plants during maturation. The group with an average degree of variation $(10.0 \%<V<20.0 \%)$ includes all other signs measured in the experiment. Factor analysis was used to optimize, interpret the calculated matrix of correlation coefficients. In the analysis of the correlation coefficient matrix, hypothetical factors with a contribution of more than $5 \%$ to the accumulated variance are calculated. The first hypothetical factor is determined by the high effects of morphophysiological features. The second factor is largely due to the contribution of plant height 30 days after germination and the extension of the panicle legs. Plant height at maturity, weight of 1000 grains make the greatest contribution to the third factor. The width of the panicle makes the greatest contribution to the accumulated dispersion of the fourth factor. The fifth factor is determined by the effects of plant height at the beginning and end of vegetation, as well as the total contribution of all studied features. 